\title{
SUMBER HISTORIS PANCASILA SEBAGAI KAJIAN SUMBER
} POLITIS PANCASILA

\author{
NAMA: ANGGITA HAPSARI \\ E-MAIL: anggitahapsari4@gmail.com \\ NO BP:20220042 \\ PERGURUAN TINGGI:AKBP-STIE “KBP” \\ PRODI: S1 MANAJEMEN \\ UAS:PENDIDIKAN PANCASILA \\ DOSEN PENGAMPU:Laurensius Arliman,SE,SH,MH.Mkn
}


PENDAHULUAN

Dilihat dai segi objek materil,pengayaab materi atau subtansi mata kuliah Pendidikan Pancasila dapat dikembangkan melalui beberapa pendkatan,diantaranya pndekatan historis,sosiologis,dan politik.Semntara dilihat dari segi objek formil,pngayaan materi mata kuliah Pendidkan Pancasila dilakukan dengan penekatan ilmiah,filosofis,dan ideologis.

Salah satu sumber pengayaan materi pendidikan Pancasila adalah berasal dari fenomena kehidupan politik bangsa Indonesia. Pola pikir untuk membangun kehidupan berpolitik yang murni dan jernih mutlak dilakukan sesuai dengan kelima sila yang mana dalam berpolitik harus bertumpu pada Ketuhanan Yang Maha Esa, Kemanusiaan yang Adil dan Beradab, Persatuan Indonesia, Kerakyatan yang Dipimpin oleh Hikmat Kebijaksanaan dalam Permusyarawatan/Perwakilan dan dengan penuh Keadilan Sosial bagi Seluruh Rakyat Indonesia tanpa pandang bulu. Etika politik Pancasila dapat digunakan sebagai alat untuk menelaah perilaku politik Negara, terutama sebagai metode kritis untuk memutuskan benar atau slaah sebuah kebijakan dan tindakan pemerintah dengan cara menelaah kesesuaian dan tindakan pemerintah itu dengan makna sila-sila Pancasila. 


\section{PEMBAHASAN}

\section{PENGERTIAN HISTORIS}

\section{A. Pengertian Historis/Sejarah}

Sejarah adalah kejadian yang terjadi pada masa lampau yang disusun berdasarkan peninggalan-peninggalan berbagai peristiwa. Peninggalan peninggalan itu disebut sumber sejarah.

Dalam bahasa Inggris, kata sejarah disebut history, artinya masa lampau; masa lampau umat manusia. Dalam bahasa Arab, sejarah disebut sajaratun (syajaroh), artinya pohon dan keturunan. Jika kita membaca silsilah raja-raja akan tampak seperti gambar pohon dari sederhana dan berkembang menjadi besar, maka sejarah dapat diartikan silsilah keturunan raja-raja yang berarti peristiwa pemerintahan keluarga raja pada masa lampau.

Ada tiga aspek dalam sejarah, yaitu masa lampau, masa kini, dan masa yang akan datang. Masa lampau dijadikan titik tolak untuk masa yang akan datang sehingga sejarah mengandung pelajaran tentang nilai dan moral.

Pada masa kini, sejarah akan dapat dipahami oleh generasi penerus dari masyarakat yang terdahulu sebagai suatu cermin untuk menuju kemajuan dalam kehidupan bermasyarakat, berbangsa, dan bernegara.

Peristiwa yang terjadi pada masa lampau akan memberi kita gambaran tentang kehidupan manusia dan kebudayaannya di masa lampau sehingga dapat merumuskan hubungan sebab akibat mengapa suatu peristiwa dapat terjadi dalam kehidupan tersebut, walaupun belum tentu setiap peristiwa atau kejadian akan tercatat dalam sejarah.

Sejarah terus berkesinambungan sehingga merupakan rentang peristiwa yang panjang. Oleh karena itu, sejarah mencakup

1. masa lalu yang dilukiskan berdasarkan urutan waktu (kronologis);

2. ada hubungannya dengan sebab akibat;

3. kebenarannya bersifat subjektif sebab masih perladanya penelitian lebih lanjut untuk mencari kebenaran yang hakiki;

4. peristiwa sejarah menyangkut masa lampau, masakini, dan masa yang akan datang.

B. Sumber Historis Pancasila Sebagai Ideologi Pancasila. 
Proses perumusan Pancasila diawali ketika dalam sidang BPUPKI pertama dr. Radjiman Widyodiningrat, mengajukan suatu masalah, khususnya akan dibahas pada sidang tersebut. Masalah tersebut adalah tentang suatu calon rumusan dasar negara Indonesia yang akan dibentuk. Kemudian tampilah pada sidang tersebut tiga orang pembicara yaitu Mohammad Yamin, Soepomo dan Soekarno.

Pada tanggal 1 Juni 1945 di dalam siding tersebut Ir. Soekarno berpidato secara lisan (tanpa teks) mengenai calon rumusan dasar negara Indonesia. Kemudian untuk memberikan nama "Pancasila" yang artinya lima dasar, hal ini menurut Soekarno atas saran dari salah seorang temannya yaitu seorang ahli bahasa yang tidak disebutkan namanya.

Pada tanggal 17 Agustus 1945 Indonesia memproklamirkan kemerdekaannya, kemudian keesokan harinya tanggal 18 Agustus 1945 disahkannya Undang-Undang Dasar 1945 termasuk Pembukaan UUD 1945 di mana didalamnya termuat isi rumusan lima prinsip atau lima prinsip sebagai satu dasar negara yang diberi nama Pancasila.

Sejak saat itulah perkataan Pancasila menjadi bahasa Indonesia dan merupakan istilah umum. Walaupun dalam alinea IV Pembukaan UUD 1945 tidak termuat istilah "Pancasila", namun yang dimaksudkan Dasar Negara Republik Indonesia adalah disebut dengan istilah "Pancasila". Hal ini didasarkan atas interpretasi historis terutama dalam rangka pembentukan calon rumusan dasar negara, yang secara spontan diterima oleh peserta sidang secara bulat.

\section{Pengertian Pancasila Menurut Para Ahli}

Berikut ini pengertian pancasila menurut para ahli:

\section{Menurut Ir. Soekarno}

Ir. Soekarno mengartikan pancasila sebagai isi jiwa bangsa Indonesia secara turun-temurun yang sekian abad lamanya terpendam bisu oleh kebudayaan barat, dengan demikian Pancasila tidak saja falsafah negara, tetapi lebih luas lagi yakni falsafah bangsa Indonesia.

\section{Menurut Prof. Dr. Drs. Raden Mas Tumenggung Notonagoro S.H.}

Pengertian pancasila menurut Notonegoro adalah dasar falsafah negara Indonesia, sehingga dapat disimpulkan bahwa Pancasila merupakan dasar falsafah dan ideologi negara yang diharapkan menjadi pandangan hidup bangsa Indonesia, sehingga dapat dijadikan sebagai dasar pemersatu, lambang persatuan dan kesatuan serta bagian pertahanan bangsa dan negara.

\section{Menurut Muhammad Yamin}


Pancasila menurut Muhammad Yamin merupakan lima dasar yang berisi pedoman atau aturan tentang tingkah laku yang penting dan baik. Pancasila berasal dari kata panca yang berarti lima dan sila berarti sendi, asas, dasar atau peraturan tingkah laku yang penting dan baik.

\section{Menurut Prof. Dr. Nurcholish Majdid}

Nurcholish mengartikan pancasila sebagai modal untuk mewujudkan demokrasi Indonesia, pancasila memberi dasar dan prasyarat asasi bagi demokrasi dan tatanan politik Indonesia, pancasila menyumbang beberapa hal penting. Menurut Nurcholish, adanya Pancasila dan UUD 1945 telah diterima oleh umat Muslim Indonesia. Sejauh ini, kedua pilar itu telah mampu menjamin kebaikan konstitusional bagi keseluruhan bangsa.

\section{Menurut Dr. Nicolaus Driyarkara SJ}

Pemikiran Driyarkara tentang Pancasila sebelum 1965, soal kesatuan dikembalikan pada hakekat manusia, sebagai yang sama dan saling bersaudara. Inilah yang menjadi titik tolak uraiannya tentang Pancasila. Kontroversi agama di Indonesia, dijelaskan dalam uraiannya tentang Pancasila dan Religi.

\section{Menurut Dr. Kuntowijoyo}

Pencetus radikalisasi pancasila ini merasa resah karena pancasila hanya dijadikan sebagai lip service bahkan dijadikan sebagai alat politik untuk melanggengkan kekuasaan. Pancasila "tidak operasional", sehingga bangsa Indonesia kehilangan arah. Pancasila memang "jimat sakti", namun jimat itu hanya disarungkan di pinggang dan tak pernah digunakan untuk "berkelahi" terhadap korupsi, apalagi dijadikan sebagai ideologi yang mengarahkan pembangunan nasional.

\section{Pengertian Politis}

Politik (dari bahasa Yunani: politikos, yang berarti dari, untuk, atau yang berkaitan dengan warga negara), adalah proses pembentukan dan pembagian kekuasaan dalam masyarakat yang antara lain berwujud proses pembuatan keputusan, khususnya dalam negara. Pengertian ini merupakan upaya penggabungan antara berbagai definisi yang berbeda mengenai hakikat politik yang dikenal dalam ilmu politik.

Poloitik adalah suatu system pemerintahan yang mengatur segala structural di dalamnya. Dalam membuat kebijakan politik harus ada aturan yang mengatur hal tersebut supaya selalu dalam jalur yang telah di tentukan.

Politik adalah seni dan ilmu untuk meraih kekuasaan secara konstitusional maupun nonkonstitusional.

Di samping itu politik juga dapat ditilik dari sudut pandang berbeda, yaitu antara lain: 
1. Politik adalah usaha yang ditempuh warga negara untuk mewujudkan kebaikan bersama (teori klasik Aristoteles)

2. Politik adalah hal yang berkaitan dengan penyelenggaraan pemerintahan dan negara

3. Politik merupakan kegiatan yang diarahkan untuk mendapatkan dan mempertahankan kekuasaan di masyarakat

4. Politik adalah segala sesuatu tentang proses perumusan dan pelaksanaan kebijakan publik.

Dalam konteks memahami politik perlu dipahami beberapa kunci, antara lain: kekuasaan politik, legitimasi, sistem politik, perilaku politik, partisipasi politik, proses politik, dan juga tidak kalah pentingnya untuk mengetahui seluk beluk tentang partai politik.

\section{B. Nilai-nilai Pancasila Sebagai Ideologi Politik}

1. Nilai Ketuhanan (Realigiusitas)

Nilai religius adalah nilai yang berkaitan dengan keterkaitan individu dengan sesuatu yang dianggapnya memiliki kekuatan sakral, suci, agung dan mulia. Memahami Ketuhahan sebagai pandangan hidup adalah mewujudkan masyarakat yang beketuhanan, yakni membangun masyarakat Indonesia yang memiliki jiwa maupun semangat untuk mencapai ridlo Tuhan dalam setiap perbuatan baik yang dilakukan.

2. Nilai Kemanusiaan (Moralitas)

Kemanusiaan yang adil dan beradab, adalah pembentukan suatu kesadaran tentang keteraturan, sebagai asas kehidupan, setiap manusia mempunyai potensi untuk menjadi manusia sempurna, yaitu manusia yang beradab.

3. Nilai Persatuan (kebangsaan) Indonesia.

Persatuan adalah gabungan yang terdiri atas beberapa bagian, kehadiran Indonesia dan bangsanya di muka bumi ini bukan untuk bersengketa. Bangsa Indonesia hadir untuk mewujudkan kasih sayang kepada segenap suku bangsa dari Sabang sampai Marauke.

4. Nilai Permusyawaratan dan Perwakilan

Sebagai makhluk sosial, manusia membutuhkan hidup berdampingan dengan orang lain, dalam interaksi itu biasanya terjadi kesepakatan, dan saling menghargai satu sama lain atas dasar tujuan dan kepentingan bersama. Prinsip kerakyatan yang menjadi cita-cita utama untuk membangkitkanbangsa Indonesia, mengerahkan potensi mereka dalam dunia modern.

5. Nilai Keadilan Sosial

Nilai keadilan adalah nilai menjunjung norma berdasarkan ketidak berpihakkan, keseimbangan, serta pemerataan terhadap suatu hal. Mewujudkan keadilan sosial bagi seluruh rakyat Indonesia merupakan cita-cita bernegara dan berbangsa. bermakna mewujudkan keadaan masyarakat yang bersatu secara organik, dimana mempunyai kesempatan yang sama untuk tumbuh dan berkembang serta belajar.

6. Perkembangan Pancasila Sebagai Ideologi Politik Sampai Sekarang Memang dalam kondisi kehidupan politik kita sekarang ini banyak diantara kita, antara lain dikalangan mereka yang memegang 
kekuasaan, yang tidak berkenan untuk mengakui kesenjangan antara nilai-nilai dasar ideologi kita dengan praktek kehidupan perpolitikan sehari-hari. Secara empiris di lapangan praktek kehidupan perpolitikan masih jauh dari, dan kadang-kadang mungkin ada yang bertentangan dengan nilai-nilai dasar yang terkandung dalam Pancasila dan UUD 1945. Keinginan agar kehidupan politik kita lebih terbuka dan lebih demokratis merupakan salah satu ukuran yang dapat kita pakai buat mengetahui kehadiran kesenjangan tersebut. Soalnya sekarang ialah apakah kita semua, termasuk yang berkuasa, memiliki kemauan politik yang kuat untuk memperbaiki kesenjangan itu.

7. Contoh Pancasila Sebagai Ideologi Terbuka Dalam Bidang Politik

Dalam bidang politik, kita harus mewujudkan perilaku, antara lain:

1. menghindari sikap dan perilaku yang memaksakan pendapat dan ingin menang sendiri;

2. penyelenggara negara dan warga negara mewujudkan nilai ke tuhanan, kemanusiaan, kebangsaan, serta kerakyatan dan ke adilan dalam kehidupan seharihari;

3. menghindari sikap menghalang-halangi orang yang akan ber partisipai dalam kehidupan demokrasi;

4. meyakini bahwa nilai-nilai Pancasila dan UUD 1945 sebagai nilai yang ter baik dan sesuai untuk bangsa Indonesia serta tidak meleceh kannya. 


\section{PENUTUP}

\section{KESIMPULAN}

Historis/Sejarah dalah kejadian yang terjadi pada masa lampau yang disusun berdasarkan peninggalan-peninggalan berbagai peristiwa. Peninggalan peninggalan itu disebut sumber sejarah.

Poloitik adalah suatu system pemerintahan yang mengatur segala structural di dalamnya. Dalam membuat kebijakan politik harus ada aturan yang mengatur hal tersebut supaya selalu dalam jalur yang telah di tentukan.gai peristiwa. Peninggalan peninggalan itu disebut sumber sejarah.

Jadi Sumber historis pancasila sebagai kajian sumber politis pancasila merupakan kejedian yang terjadi pada masa lampau tetntang bagaimana pancasil di ciptakan,dan politis merupakan system yang mengatur segala stuctural didalam nya.

Dalam sumber politik, kita harus mewujudkan perilaku, antara lain:

> menghindari sikap dan perilaku yang memaksakan pendapat dan ingin menang sendiri;

> penyelenggara negara dan warga negara mewujudkan nilai ke tuhanan, kemanusiaan, kebangsaan, serta kerakyatan dan ke adilan dalam kehidupan seharihari;

> menghindari sikap menghalang-halangi orang yang akan ber partisipai dalam kehidupan demokrasi;

> meyakini bahwa nilai-nilai Pancasila dan UUD 1945 sebagai nilai yang ter baik dan sesuai untuk bangsa Indonesia serta tidak meleceh kannya. 


\subsection{Saran dan kritik}

Adapun saran dari penulis sebaaiknya pembaca dapat memahami materi terlebih dahulu.

Demikian Makalah ini penulis buat agar dapat bermanfaat bagi para pembaca,jika ada kesalahan mohon sekiranya pembaca memberi kritik yang membangun agar dapat memyempurnakan makalah ini.Sekian dan terimakasih.

\section{DAFTAR PUSTAKA}

Darmini Roza dan Laurensius Arliman S Peran Pemerintah Daerah Di Dalam Melindungi Hak Anak Di Indonesia, Masalah-Masalah Hukum, Volume 47, Nomor 1, 2018.

Laurensius Arliman S, Komnas HAM dan Perlindungan Anak Pelaku Tindak Pidana, Deepublish, Yogyakarta, 2015.

Laurensius Arliman S, Penguatan Perlindungan Anak Dari Tindakan Human Trafficking Di Daerah Perbatasan Indonesia, Jurnal Selat, Volume 4, Nomor 1, 2016.

Laurensius Arliman S, Problematika Dan Solusi Pemenuhan Perlindungan Hak Anak Sebagai Tersangka Tindak Pidana Di Satlantas Polresta Pariaman, Justicia Islamica, Volume 13, Nomor 2, 2016.

Laurensius Arliman S, Pelaksanaan Perlindungan Anak Yang Tereksploitasi Secara Ekonomi Oleh Pemerintah Kota Padang, Veritas et Justitia, 
Volume 2, Nomor 1, 2016.

Laurensius Arliman S, Kedudukan Ketetapan MPR Dalam Hierarki Peraturan Perundang-Undangan Di Indonesia, Lex Jurnalica, Volume 13, Nomor 3 , 2016.

Laurensius Arliman S, Komnas Perempuan Sebagai State Auxialiary Bodies Dalam Penegakan Ham Perempuan Indonesia, Justicia Islamica, Volume 14, Nomor 2, 2017.

Laurensius Arliman S, Peranan Pers Untuk Mewujudkan Perlindungan Anak Berkelanjutan Di Indonesia, Jurnal IImu Hukum Tambun Bungai, Volume 2, Nomor 2, 2017.

Laurensius Arliman S, Mewujudkan Penegakan Hukum Yang Baik Untuk Mewujudkan Indonesia Sebagai Negara Hukum, Jurnal Hukum Doctrinal, Volume 2, Nomor 2, 2017.

Laurensius Arliman S, Participation Non-Governmental Organization In Protecting Child Rights In The Area Of Social Conflict, The 1st Ushuluddin and Islamic Thought International Conference (Usicon), Volume 1, 2017.

Laurensius Arliman S, Partisipasi Masyarakat Dalam Pembentukan Perundang-Undangan Untuk Mewujudkan Negara Kesejahteraan 
Indonesia, Jurnal Politik Pemerintahan Dharma Praja, Volume 10, Nomor 1, 2017, https://doi.org/10.33701/jppdp.v10i1.379.

Laurensius Arliman S, Peran Komisi Perlindungan Anak Indonesia Untuk Mewujudkan Perlindungan Anak, Jurnal Respublica Volume 17, Nomor $2,2018$.

Laurensius Arliman S, Menjerat Pelaku Penyuruh Pengrusakan Barang Milik Orang Lain Dengan Mempertimbangkan Asas Fungsi Sosial, Jurnal Gagasan Hukum, Volume 1, Nomor 1, 2019.

Laurensius Arliman S, Ilmu Perundang-Undangan Yang Baik Untuk Negara Indonesia, Deepublish, Yogyakarta, 2019.

Laurensius Arliman S, Isdal Veri, Gustiwarni, Elfitrayenti, Ade Sakurawati, Yasri, Pengaruh Karakteristik Individu, Perlindungan Hak Perempuan Terhadap Kualitas Pelayanan Komnas Perempuan Dengan Kompetensi Sumber Daya Manusia Sebagai Variabel Mediasi, Jurnal Menara Ekonomi: Penelitian dan Kajian Ilmiah Bidang Ekonomi, Volume 6, Nomor 2, 2020.

Laurensius Arliman S, Pendidikan Kewarganegaraan, Deepublish, Yogyakarta, 2020 .

Laurensius Arliman S, Makna Keuangan Negara Dalam Pasal Pasal 23 E 
Undang-Undang Dasar 1945, Jurnal Lex Librum, Volume 6, Nomor 2 Juni 2020, http://dx.doi.org/10.46839/llih.v6i2.151.

Laurensius Arliman S, Kedudukan Lembaga Negara Independen Di Indonesia Untuk Mencapai Tujuan Negara Hukum, Kertha Semaya Journal IImu Hukum, Volume 8, Nomor 7, 2020.

Laurensius Arliman S, Pelaksanaan Assesment Oleh Polres Kepulauan Mentawai Sebagai Bentuk Pelaksanaan Rehabilitasi Bagi Pecandu Dan Korban Penyalahgunaan Narkotika, Jurnal Muhakkamah, Volume 5, Nomor 1, 2020.

Laurensius Arliman S, Aswandi Aswandi, Firgi Nurdiansyah, Laxmy Defilah, Nova Sari Yudistia, Ni Putu Eka, Viona Putri, Zakia Zakia, Ernita Arief, Prinsip, Mekanisme Dan Bentuk Pelayanan Informasi Kepada Publik Oleh Direktorat Jenderal Pajak, Volume 17, No Nomor, 2020.

Larensius Arliman S, Koordinasi PT. Pegadaian (Persero) Dengan Direktorat Reserse Narkoba Polda Sumbar Dalam Penimbangan Barang Bukti Penyalahgunaan Narkotika, UIR Law Review, Volume 4, Nomor 2, 2020, https://doi.org/10.25299/uirlrev.2020.vol4(1).3779.

Laurensius Arliman S, Tantangan Pendidikan Kewarganegaraan Pada Revolusi 4.0, Ensiklopedia Sosial Review, Volume 2, Nomor 3, 2020. 
Muhammad Afif dan Laurensius Arliman S, Protection Of Children's Rights Of The Islamic And Constitutional Law Perspective Of The Republic Of Indonesia, Proceeding: Internasional Conference On Humanity, Law And Sharia (Ichlash), Volume 1, Nomor 2, 2020.

Otong Rosadi danLaurensius Arliman S, Urgensi Pengaturan Badan Pembinaan Idelogi Pancasila Berdasarkan Undang-Undang Sebagai State Auxiliary Bodies yang Merawat Pancasila dalam Perspektif Hak Asasi Manusia, Prosiding Konferensi Nasional Hak Asasi Manusia, Kebudayaan dan Tujuan Pembangunan Berkelanjutan Indonesia pada Masa Pandemi Covid-19: Tantangan untuk Keilmuan Hukum dan Sosial Volume 1, Universitas Pancasila, Jakarta, 2020. 